\title{
Analisis Rasio Keuangan Bank Pembangunan Daerah di Indonesia (Studi Empiris pada Bank Jambi Periode 2017 s/d 2019)
}

\author{
Indah Osi $^{1^{*}}$, Sugeng Prayitno ${ }^{2}$, Iqra Wiarta ${ }^{3 *}$, Endah Tri Kurniasih $^{4}$ \\ 1,2,3,4 Universitas Muhammadiyah Jambi \\ *Correspondence email: osiwardani@gmail.com: it.sugengprayitno@gmail.com: iqra_wiarta2006@yahoo.co.id: \\ endah.trikurniasih@gmail.com
}

\begin{abstract}
The regional development bank is part of the financial services industry in Indonesia. Regional development banks in addition to intermediation in the financial system also have an important role for the region, namely as a source of income for the region. That is why a good asset quality assessment is required in order for the regional development bank to provide dividends and survive in the financial services industry. This research aims to find out and analyze the asset quality of regional development banks in Indonesia with case studies on jambi regional development bank or commonly abbreviated jambi bank. The research method used is quantitative analysis with sourced in secondary data taken from the annual report of Jambi bank for the period 2017 to 2019 with an assessment of the assessment of bank Indonesia regulation number 14/15/PBI/2012. The results of the study are capital ratio, asset quality, rentability and liquidity of jambi banks as a whole to achieve a good ratio in the period 2017 to 2019.
\end{abstract}

Keywords : Capital, Asset Quality, and Rentability

\section{Pendahuluan}

Bank merupakan badan usaha yang kegiatanya menghimpun dana dari masyarakat dalam bentuk simpanan dan menyalurkanya kepada masyarakat dalam bentuk kredit dan bentuk lainya dalam rangka meningkatkan taraf hidup rakyat. Untuk dapat menilai kinerja sebuah bank maka diperlukan analisa terhadap laporan keuangan bank atau perusahaan. Menurut hanafi dan halim (2009) Laporan keuangan perusahaan merupakan salah satu sumber informasi yang penting di samping informasi lain seperti informasi industri, kondisi perekonomian, pangsa pasar perusahaan, kualitas manajemen, dan lainnya. Tingkat persaiangan industri perbankan di Indonesia saat ini sangat ketat. Pada tahun 2019 tercatat sebanyak 110 bank umum yang ada di Indonesia. Selain itu terdapat pesaing baru sektor perbankan yaitu dengan munculnya perusahaan yang berbasiskan financial teknologi. Salah satu kategori perbankan yang ada di tanah air yaitu Bank pembangunan daerah (BPD). BPD merupakan bank yang kepemilikan mayoritasnnya dimiliki oleh pemerintah daerah kabupaten/kota serta provinsi yang ada di Indonesia. Berdasarkan berita CNBC pada tangggal 23 Februari 2020 dana yang dikelola oleh bank Pembangunan Daerah se Indonesia mencapai 576 T. Salah satu bank pembangunan daerah yaitu bank Jambi. berdasarkan laporan tahun 2019 dana pihak ketiga pada bank pembangunan ini berjumlah Rp. 7.324.456.000.000,-.

Dengan besarnya dana kelolaan yang terdapat di Bank Pembangunan daerah dan juga semakin ketatnya persaingan disektor perbankan maupun sektor keuangaan pada umumnya mengharuskan bank menjalankan usahanya berdasarkan prinsip kehati-hatian. Untuk itu Bank Indonesia membuat peraturan nomor 14 tahun 2014 tentang penialain kualitas aset dan juga peraturan bank indonesia nomor 13 tahun 2011 tentang penilaian tingkat kesehatan bank. Bertolok dari latar belakang diatas, peneliti tertarik untuk melakukan penelitian lebih lanjut tentang kinerja keuangan Bank pembangunan daerah studi empiris pada bank Jambi periode 2017 sampai dengan 2019.

Tujuan dari Penelitian ini yaitu untuk mengetahui dan menganalisis kinerja keuangan bank pembangunan daerah studi pada bank jambi yang merupakan salah satu bank pembangunan daerah yang ada di Indonesia periode 2017 sampai dengan 2019 dengan tolok ukur kinerja keuangannya yaitu peraturan bank Indonesia nomor 14 tahun 2014

\section{Landasan Teoritis \\ Kinerja Keuangan Bank}

Kinerja Keuangan bank merupakan penilaian kesehatan bank sebagian besar merupakan analisis kinerja keuangan yang diatur sesuai dengan ketentuan Bank Indonesia yang bersumber dari laporan keuangan yang berisikan tentang rasio-rasio keuangan. Menurut Haryati (2001) Penelitian tentang rasio keuangan perbankan yang digunakan untuk meramal kebangkrutan telah dilakukan tahun 1977 oleh Altman, Holdeman dan Narayan. Adapun kinerja keuangan yang dinilai dalam penelitian ini yaitu : 


\section{Kualitas Aset}

Penilaian profil risiko merupakan penilaian terhadap kualitas penerapan manajemen risiko dalam operasional bank yang dilakukan terhadap 8 (delapan) risiko akan tetapi dari 8 risiko perbankan tersebut, jenis risiko yang menonjol dalam industri perbankan nasional adalah risiko kredit dan operasional. Hal ini merupakan konsekuensi dari usaha perbankan yang mayoritas masih mengandalkan penyaluran kredit. Dari sisi risiko kredit, hal-hal yang masih perlu ditingkatkan pada beberapa bank antara lain adalah penyempurnaan kebijakan dan internal control bank. Sementara itu, untuk risiko operasional perlu ditingkatkan kualitas SDM serta infrastruktur teknologi.

\section{Rentabilitas}

Penilaian terhadap faktor rentabilitas (earnings) meliputi penilaian terhadap kinerja earnings, sumber-sumber earnings, dan sustainability earnings bank. Tindakan pengawasan yang dilakukan antara lain meminta bank agar meningkatkan kemampuan menghasilkan laba seperti melalui peningkatan efisiensi dan volume usaha dengan tetap memperhatikan prinsip kehati-hatian.

\section{Permodalan}

Penilaian terhadap faktor permodalan (capital) meliputi penilaian terhadap tingkat kecukupan permodalan dan pengelolaan permodalan. Bagi bank yang dinilai masih perlu meningkatkan modal untuk mendukung kegiatan usaha, Bank Indonesia antara lain meminta agar pemegang saham bank menambah modal, mencari investor baru dan/atau mengurangi proporsi pembagian dividen kepada pemegang saham. Hal ini dilakukan dengan beberapa pertimbangan yaitu krisis ekonomi global, perkembangan standar internasional dan menghilangkan potensi duplikasi dalam penilaian TKS. Seiring dengan perubahan tersebut, terhitung mulai posisi Desember 2011 penilaian tingkat kesehatan bank dengan metode RBBR pada kondisi normal dilakukan secara berkala setiap 6 bulan.

Dalam melakukan penilaian tingkat kesehatan bank, Bank Indonesia mewajibkan bank untuk menyampaikan hasil penilaian (self assessment) tingkat kesehatan paling lambat 1 (satu) bulan setelah periode penilaian. Self assessment yang dilakukan bank tersebut selanjutnya digunakan Bank Indonesia sebagai bahan pertimbangan dalam menilai tingkat kesehatan bank. Tindak lanjut pengawasan yang dilakukan Bank Indonesia terkait dengan penilaian TKS adalah meminta manajemen bank untuk melakukan langkah perbaikan dan melaporkannya secara berkala yang akan dipertimbangkan dalam menilai tingkat kesehatan dan tindakan pengawasan selanjutnya. Peringkat Komposit (PK) tingkat kesehatan bank ditetapkan berdasarkan analisis secara komprehensif dan terstruktur terhadap peringkat setiap faktor dengan memperhatikan materialitas dan signifikansi masing-masing faktor, serta mempertimbangkan kemampuan bank dalam menghadapi perubahan kondisi eksternal yang signifikan.

Tabel 1

Operasional Variabel

\begin{tabular}{|c|c|c|}
\hline Kinerja Keuangan & Keterangan & Formula \\
\hline Kualitas Aset & $\begin{array}{l}\text { Dalam Penelitian ini risiko profil yang digunakan yaitu } \\
\text { NPL. Non Performing Loan yaitu Ratio adalah ukuran } \\
\text { kemampuan bank dalam menyediakan dana terhadap para } \\
\text { debiturnya. }\end{array}$ & $N P L=\frac{\text { Kredit Non Produktif }}{K A P} \times 100 \%$ \\
\hline Rentabilitas & $\begin{array}{l}\text { Pada penelitian ini rasio yang digunakan adalah ROA. } \\
\text { Return on Asset ratio adalah kemampuan suatu bank dalam } \\
\text { menghasilkan keuntungan sebelum pajak pada periode } \\
\text { tertentu dari total aset yang dimiliki }\end{array}$ & $R O A=\frac{E B I R}{\text { Total Aktiva }} X 100 \%$ \\
\hline Permodalan & $\begin{array}{l}\text { Rasio permodalan yang digunakan yaitu rasio kecukupan } \\
\text { modal atau CAR. }\end{array}$ & $C A R=\frac{\text { Modal }}{A T M R} \times 100 \%$ \\
\hline
\end{tabular}

\section{Metode}

Pada penelitian ini data yang digunakan adalah data sekunder yang bersumber dari laporan tahunan Bank Jambi yang dijadikan sebagai objek dari penelitian tersebut pada periode 2017 sampai dengan 2019 yang di unduh pada halaman website Bank Jambi. Dalam melakukan penelitian ini, data yang diperoleh akan dianalisis dengan menggunakan pendekatan kuantitatif. Penelitian kuantitatif merupakan metode penelitian yang berusaha untuk mengkuantifikasi data, menggeneralisasi hasil dari sampel pada populasi yang terkait, dan khususnya menerapkan beberapa bentuk analisis statistik.

\section{Hasil}

Penilaian terhadap kualitas aset merupakan sebuah perhitungan besarnya indikator risiko kredit dalam sebuah Bank. Adapun penilaian terhadap risiko kredit pada penilitian ini yaitu melalui penilaian terhadap rasio NPL dari bank Jambi periode 2017 - 2019. Rasio NPL merupakan salah satu indikator yang dapat dijadikan tolak ukur terhadap 
Indah Osi et al, Analisis Rasio Keuangan Bank Pembangunan Daerah di Indonesia (Studi Empiris pada Bank Jambi Periode 2017 s/d 2019)

kesehatan aset suatu bank. Kinerja NPL dari Bank Jambi periode 2017 sampai dengan 2019 dapat dilihat pada tabel dibawah ini.

Tabel 2

Kinerja NPL Bank Jambi Periode 2017 - 2019

\begin{tabular}{|c|c|c|c|}
\hline Tahun & Rasio NPL & Pengukuran & Kriteria \\
\hline 2017 & $0.10 \%$ & $\mathrm{NPL}<2 \%$ & Sangat Sehat \\
\hline 2018 & $0.12 \%$ & $\mathrm{NPL}<2 \%$ & Sangat Sehat \\
\hline 2019 & $0.44 \%$ & $\mathrm{NPL}<2 \%$ & Sangat Sehat \\
\hline
\end{tabular}

Sumber : Annual Report Bank Jambi 2019

Berdasarkan data diatas didapatkan bahwa penilaian terhadap NPL bank Jambi dari tahun 2017 sampai dengan 2019 selalu mengalami perubahaan. Rasio NPL tertinggi terdapat pada tahun 2019 yaitu sebesar $0.44 \%$ dan terendah terjadi pada tahun 2017 yaitu sebesar $0.10 \%$. secara keseluruhan nilai NPL bank Jambi selama periode 2017 sampai dengan 2019 berada dibawah 2\%. Dengan demikian menunjukan bahwa rasio kualitas aset bank jambi berada dalam kriteria sangat sehat sesuai dengan peraturan Bank Indonesia. Penilaian terhadap faktor rentabilitas (earnings) meliputi penilaian terhadap kinerja earnings, sumber-sumber earnings, dan sustainability earnings bank. Dalam penelitian ini rasio keuangan yang dilakukan analisis yaitu rasio ROA. Rasio ROA merupakan kemampuan perusahaan menghasilkan laba dari penggunaan sumber daya atau aset yang dimilikinya. Adapun perkembangan terhadap ROAbank Jambi periode 2017 sampai dengan 2019 dapat dilihat pada tabel dibawah ini :

Tabel 3

Kinerja ROA Bank Jambi Periode 2017 - 2019

\begin{tabular}{|c|c|c|c|}
\hline Tahun & Rasio ROA & Pengukuran & Kriteria \\
\hline 2017 & $3,65 \%$ & $\mathrm{ROA}>2 \%$ & Sangat Sehat \\
\hline 2018 & $3,06 \%$ & $\mathrm{ROA}>2 \%$ & Sangat Sehat \\
\hline 2019 & $2,72 \%$ & $\mathrm{ROA}>2 \%$ & Sangat Sehat \\
\hline
\end{tabular}

Sumber : Annual Report Bank Jambi 2019

Bertolok dari Tabel diatas diketahui bahwa dari tahun 2017 sampai dengan 2019 kinerja rasio ROA Bank Jambi berada pada kriteria sangat Sehat. Ini dapat dilihat dari rasio ROA Bank Jambi dari tahun 2017 sampai dengan 2019 selalu berada pada nilai rasio lebih besar dari $2 \%$ yang berarti sangat sehat. Penilaian terhadap faktor permodalan (capital) meliputi penilaian terhadap tingkat kecukupan permodalan dan pengelolaan permodalan. Pada penelitian ini rasio yang digunakan dalam menilai permodalan Bank Jambi yaitu CAR. Adapun nilai dari CAR Bank Jambi dapat dilihat pada tabel di bawah ini :

Tabel 4

Kinerja CAR Bank Jambi Periode 2017 - 2019

\begin{tabular}{|c|c|c|c|}
\hline Tahun & Rasio CAR & Pengukuran & Kriteria \\
\hline 2017 & $29.48 \%$ & $\mathrm{CAR}>15 \%$ & Sangat Sehat \\
\hline 2018 & $28.1 \%$ & $\mathrm{CAR}>15 \%$ & Sangat Sehat \\
\hline 2019 & 22,78 & CAR > $15 \%$ & Sangat Sehat \\
\hline
\end{tabular}

Sumber : Annual Report Bank Jambi 2019

Berdasarkan tabel diatas dapat diketahui bahwa tingkat rasio CAR Bank Jambi selama 3 tahun dari tahun 2017 sampai dengan 2019 selalu berada di atas 15\%. Artinya bahwa kinerja permodalan yaitu CAR Bank Jambi sangat baik selama tiga tahun berturut - turut dan masuk pada kategori atau kriteri Bank dengan tingkat kesehatan sangat sehat.

\section{Simpulan}

Penelitian ini bertujuan untuk mengetahui dan menganalisis kinerja keuangan bank pembangunan daerah studi empiris pada bank jambi periode 2017 sampai dengan 2019 dengan tolok ukur peraturan Bank Indonesia no 14 tahun 2014. Berdasarkan hasil penelitian menunjukan bahwa seluruh kinerja keuangan bank jambi menunjukan kinerja yang baik dengan tingkat kinerja sangat sehat mulai dari tahun 2017 hingga tahun 2019.

\section{Daftar Pustaka}

Cahyaningrum, Ndaru Hesti, 2012, Analisis Rasio Keuangan dalam Memprediksi Pertumbuhan Laba (Studi Kasus : Perusahaan Manufaktur yang Terdaftar di Bursa Efek Indonesia Periode 2005 sampai dengan 2010), Semarang : Fakultas Ekonomika dan Bisinis Universitas Diponegoro. 
Dendawijaya, Lukman. 2009. Manajemen Perbankan. Bogor: Ghalia Indonesia.

Hapsari, Epri Ayu, 2007, Analisis Rasio Keuangan untuk Memprediksi Pertumbuhan Laba (Studi Kasus : Perusahaan Manufaktur yang Terdaftar di Bursa Efek Jakarta Periode 2001 sampai dengan 2005), Semarang : Program Studi Magister Manajemen Program Pasca Sarjana Universitas Diponegoro.

Hanafi, Mamduh M dan Abdul Halim (2009), Analisis Laporan Keuangan, edisi 4, STIM YKPN, Yogyakarta Haryati, Sri, 2001, Analisis Kebangkrutan Bank. Jurnal ekonomi dan bisnis Indonesia, Jakarta: STIE Perbanas Yudha Wirawan, Rizki. 2013. Analisis Tingkat Kesehatan KeuanganTerhadap Pertumbuhan Laba Pada Perusahaan BUMN sektor Perbankan di Indonesia. Skripsi S1 Program Manajemen Universitas Hasanudin.

Riyanto, Bambang, 2001, Dasar-dasar Pembelanjaan Perusahaan, edisi kelima, BPFE, Yogyakarta

Peraturan Bank Indonesia Nomor 6/10/PBI/2004 tentang Sistem Penilaian Kesehatan Bank Umum. 2004. Jakarta: Bank Indonesia.

Peraturan Bank Indonesia Nomor 13/24/DPNP/2011 tentang Sistem Penilaian Kesehatan Bank Umum. 2011. Jakarta: Bank Indonesia.

Putri, Hana Tamara, 2016, Analisis Pengaruh Rasio Keuangan RBBR Terhadap Pertumbuhan Laba Bank (Studi Kasus PT. Bank Central Asia (BCA) Tbk), Jurnal ilmiah Universitas Batanghari Jambi.

Wiarta, Iqra dkk, 2017, Analisis kinerja keuangan Bank Tabungan Negara Terhadap Tingkat Kesehatan perbankan, Prosiding seminar nasional Aimi 